\title{
Reaching the golden milestone. The 2013 ERS Dublin summit: preparing the road to Rome
}

\author{
Francesco Blasi', Maeve Barry² and Brian Ward ${ }^{2}$
}

Affiliations: 'Dipartimento Fisiopatologia Medico-Chirurgica e dei Trapianti, University of Milan, IRCCS Fondazione Cà Granda, Milan, Italy. ${ }^{2}$ European Respiratory Society, European Affairs Dept, Brussels, Belgium.

Correspondence: B. Ward, European Respiratory Society, European Affairs Dept, 49-51 Rue de Tréves, BE-1040, Brussels, Belgium. E-mail: brian.warddersnet.org

@ERSpublications

ERS Presidential Summit in Dublin identifies priority research topics http://ow.ly/nlATy

The Milliarium Aureum (or golden milestone) was a monument erected by the Emperor Caesar Augustus near the Temple of Saturn in the central forum of ancient Rome, Italy. All roads were considered to begin from this monument and all distances in the Roman Empire were measured relative to that point. To travel a road and to reach a milestone, one often needs a roadmap. At the first Annual Presidential Summit in Leuven, Belgium, in 2011, the European Respiratory Society (ERS) reflected on what must be done to prevent the rise of respiratory diseases in the future and produced the European Respiratory Roadmap [1,2]. This roadmap has served as a guide to subsequent summits as they address the varying and complex issues of policy as it relates to respiratory medicine. The summits have developed into key advocacy events where the leadership of the ERS interacts with a wide range of decision makers in Europe relevant to respiratory medicine. Last year's summit in Tallinn, Estonia, focused on the austerity of the times we live in and the rise of health inequalities in Europe [3]. Next year with the opening of the Italian Presidency of the European Union, the summit will travel the road from basic science to translational research and will arrive in Rome [4].

\section{Justifying the need for research on lung health}

The objective of this year's 2013 Presidential Summit in Dublin, Ireland, was to identify priority research topics that should be addressed at European level. All stakeholders were involved: medical professionals, patients, pharmaceutical industry representatives, research funders and research policymakers.

The Director of the Irish Research Council, E. Meehan, gave the keynote address to the summit. She emphasised that from a policy and research-funding perspective, it is clear that across Europe there is an ever-increasing emphasis on co-ordination of endeavour across research arenas, whether at the individual researcher or group level. In parallel to this there is an ever-increasing emphasis on researchers engaging with "knowledge users", not just at the point when there are research outputs, but also at the stage when research questions are being developed and throughout the research lifecycle. The current economic climate and the significant societal challenges that face us are accelerating the demand for a more integrated and responsive research system. This demand has brought to the fore debates on what is "useful" research and has put the spotlight on the significant cultural and philosophical differences as to why we do research, what research should be conducted (and funded) and who should decide [5].

Received: July 152013 | Accepted after revision: July 172013

Conflict of interest: M. Barry and B. Ward are employees of the European Respiratory Society. 


$\begin{aligned} & \text { TABLE } 1 \text { European Respiratory Society research priorities from the Dublin Presidential } \\ & \text { Summit }\end{aligned}$
$\begin{aligned} & \text { Research gaps } \\ & \begin{array}{l}\text { Individual lifestyle and interaction with risk } \\ \text { factors: the impact on lung health from } \\ \text { prenatal to ageing lung } \\ \text { Infectious disease and antimicrobial resistance }\end{array}\end{aligned} \begin{array}{r}\text { Development of a virtual lung to create a dynamic } \\ \text { system against which to test nutritional, environmental } \\ \text { and other factors; extended birth cohort studies } \\ \text { Tuberculosis elimination [7]: launch of elimination- } \\ \text { oriented basic research for vaccines }\end{array}$
$\begin{gathered}\text { Personalised medicine } \\ \text { Responders versus non responders biology; focus on } \\ \text { "omics" and deep phenotyping; investigation of } \\ \text { biomarkers }\end{gathered}$

\section{The post-2013 European Union funding instrument}

Horizon 2020 will attempt to find a balance in this debate by funding research excellence, research to address grand challenges and innovation initiatives [6]. In addressing the grand challenge of health demographic change and well-being, the funding programme is divided into 16 themes. These range from health determinants, screening and understanding of disease to in silico medicine, vaccine and health data. Research topics will move from disease-specific issues towards these broader biomedical areas. Given this shift, it was important that the summit was able to provide lung health researchers with an opportunity to prepare priorities and potential proposals in the presence of the European Commission, who will be responsible for research calls in Horizon 2020 (table 1).

If we are to be successful in meeting Europe's priorities for research, novel and diverse elements will need to be brought together. We need to realign how we view lung disease and consider a new taxonomy of disease in general. In order to successfully prepare for Horizon 2020, the lung health researcher must employ the three "I"s: be more interdisciplinary, intersectorial and international when applying for funding.

\section{A thousand roads lead men forever to Rome}

Horizon 2020 and other public programmes present an enormous opportunity to reach our goal to advance research in lung health, but there are other ways, for example through private sector funding. Research funding from the private sector can be controversial [8]. However, we must be realistic in these economic times. While the budgets for public research funding are being cut and national foundations are receiving fewer donations, crucial research still needs to be carried out. Public-private partnerships are needed if we are to make new discoveries and advance the science of respiratory medicine. If we are to be successful, we need to foster more large-scale industry collaboration and engagement with the scientific community, promote more active involvement of patients, regulators and payers, and enable innovation via joint effort rather than alone [9].

One successful partnership that was debated at the summit was the innovative medicines initiative (IMI) [10]. It was pointed out that IMI projects are delivering robust validated models for drug development. In addition, biomarkers and tools predictive of clinical outcomes, efficacy and safety, and potential new drug targets are being created. Projects are even funding the education and training for a new generation of research and development scientists and improvement of the design and process of clinical trials. They are also engaging in "Big Data" solutions to leverage knowledge essential if personalised medicine is to become a reality. It is foreseen that there will be an IMI2 under Horizon 2020. The ERS must engage with this. The plan for IMI2 is that the initiative should be expanded in scope and should address the entire life science research and innovation value chain [11]. It should also cover all life science industries in a modular and flexible set-up and focus on addressing public health needs.

\section{Patients as partners}

These new partnerships should not neglect their end goal, the patients. It is logical that patients be consulted in research priority setting [12]. This message was clearly and convincingly brought across at the summit by a number of patient representatives. At a point in the research and innovation chain, patients are fundamental actors. As a result, there is a need for enhanced communication. Patients should be better informed of possibilities for involvement in trials and studies, but also for support and guidance once these steps are underway. The move towards personalised medicine aspires to cure rather than suppress disease, which represents a huge shift in treatment and engagement with patients [13]. To encourage full and active participation, patients and their families need to be fully informed at all stages. Adherence to treatment 
TABLE 2 European Respiratory Society (ERS) and public health research

Full implementation of the WHO Framework Convention on Tobacco Control [15]

Parma Declaration [1]

Reduction of health inequalities within and between the European Union member states Development of cost-effective early diagnosis and screening

Collaboration with the European Union to establish registries and guidelines on asthma and COPD at European level
Collaboration opportunities for the Tobacco Control Committee; the ERS has also called for more research on e-cigarettes

Potential opportunities for the ERS Environment and Health Committee; actions to be followed up and enacted by the European Union member states with an increased focus on environmental factors, especially air quality

Focus of last year's summit will continue to remain a priority of the ERS

A key recommendation of the ERS to policy makers, which will require ongoing clinical research

The ERS has consistently called for this and is a member of the European Chronic Disease Alliance

[16], which advocates for a European Union level strategy for chronic diseases

WHO: World Health Organization; COPD: chronic obstructive pulmonary disease.

within and beyond trials can best be ensured through education and communication. As a medical society, the ERS has a responsibility to play a role in this process. We cannot assess and outline research priorities without involving the end beneficiaries. Current projects which the ERS are involved in, such as the PROactive chronic obstructive pulmonary disease project [14], provide an excellent example of putting patient involvement into practice.

\section{Rome and beyond}

As medical professionals it is our responsibility to act and use our expertise, not only to treat patients, but to join wider public health efforts aimed at preventing illness (table 2). Through the ERS Advocacy Committee, the ERS has firmly established itself as a credible stakeholder in the policy sphere. Advocacy matters, it can and does make a difference, and next year the ERS will continue to promote lung health under the Italian Presidency of the European Union. Another milestone is the publication of the White Book [17]. This publication brings home to European leaders the burden of respiratory disease and the steps they can implement to reduce and prevent this burden. We are confident that the ERS will continue to be heard, as an advocate for policy, research and science. Next year's summit will see this dialogue move towards addressing translational medicine. Awareness of the importance of lung health is a step-by-step process which needs a constant effort. After all, Rome was not built in a day!

\section{References}

Sibille Y, Decramer M, Nicod LP, et al. Directing the future of lung health: the European Respiratory Roadmap. Eur Respir J 2011; 38: 502-506.

Decramer M, Sibille Y, eds. European Respiratory Roadmap. Sheffield, European Respiratory Society, 2011. Rabe KF, Ward B. Uncovering and tackling Europe's hidden respiratory illness. Lancet 2012; 380: 623-624. Blasi F, Barnes PJ, Gaga M, et al. Future directions for the ERS: Presidential plans. Eur Respir J 2013; 42: 875-880. Jump P. ERC rejects "impact agenda". Times Higher Education. March 8, 2012. www.timeshighereducation.co.uk/ 419276.article

6 European Commission. Research and Innovation. Horizon 2020. http://ec.europa.eu/research/horizon2020/ index_en.cfm Date last accessed: July 12, 2013. Date last updated: May 30, 2013.

7 Diel R, Loddenkemper R, Zellweger J-P, et al. Old ideas to innovate tuberculosis control: preventive treatment to achieve elimination. Eur Respir J 2013; 42: 786-802.

8 Desmond-Hellmann S. Improving health with partnerships between academia and industry. JAMA Intern Med 2013; 173: 1051-1052.

9 Decramer S, Decramer M. Who can pay for innovative medicines? Eur Respir J 2013; 41: 495-496.

10 Kamel N, Compton C, Middelveld R, et al. The Innovative Medicines Initiative (IMI): a new opportunity for scientific collaboration between academia and industry at the European level. Eur Respir J 2008; 31: 924-926.

11 European Federation of Pharmaceutical Industries and Associations. IMI2. www.efpia.eu/topics/innovation/ innovative-medicines-initiative/innovative-medicines-initiative-2 Date last accessed: July 12, 2013.

12 Elberse J, Laan D, de Cock Buning T, et al. Patient involvement in agenda setting for respiratory research in the Netherlands. Eur Respir J 2012; 40: 508-510.

13 Palange P, Busari J, Hare A, et al. Perspectives in medical education: signposts to the future in educating respiratory specialists. Eur Respir J 2012; 39: 520-524. 
14 PROactive COPD. www.proactivecopd.com Date last accessed: July 11, 2013.

15 Decramer M, Sibille Y, Bush A, et al. The European Union conference on chronic respiratory disease: purpose and conclusions. Eur Respir J 2011; 37: 738-742.

16 European Chronic Disease Alliance. www.alliancechronicdiseases.org Date last accessed: July 12, 2013.

17 Gibson GJ, Loddenkemper R, Sibille Y, et al. European Lung White Book. 2nd Edn. Sheffield, European Respiratory Society, 2013. 